\title{
A hybrid air conditioning system using solar energy to save electrical energy with improving performance
}

\author{
Ahmed Al-Okbi ${ }^{1,2, *}$, Yuri Vankov ${ }^{1}$, and Hasanen Mohammad Hussain ${ }^{2}$ \\ ${ }^{1}$ Kazan State Power Engineering University, Kazan, Russia \\ ${ }^{2}$ University of Technology, Baghdad 10001, Iraq
}

\begin{abstract}
The process of operating an air conditioning system by hybrid energy that uses solar energy for purpose of saving electrical energy with improving the performance from modern and environmentally friendly systems. With high demand for air-conditioning systems in summer in hot regions, especially in Iraq due to high temperatures, the issue of using renewable energies becomes more attractive due to the continuous interruption of electrical energy. Air conditioners in Iraq consume more than half of the average electricity production. Therefore, saving energy leads to ensuring the reliability of electricity and reduces the consumption of fuel and gases that pollute the environment and negatively affect on the ozone layer. In the current research, the atmosphere of the city Baghdad was used to collect the solar thermal energy through a vacuum solar collector and combine it with a conventional air conditioner in order to reduce the electrical energy consumption on the compressor and increase the coefficient of performance. Several tests were conducted on the experimental device for comparing results with the conventional device and evaluating performance. The results showed that the performance with the vacuum solar collector became more efficient 8.97 instead of 4.27 than with the conventional system, and the energy consumption decreased by $52 \%$.
\end{abstract}

\section{Introduction}

The huge demand on air-conditioning systems in summer in hot regions, especially in Iraq, leads to consumption high electrical energy, which effect on its reliability and consumes a large quantity of fuel, which negatively effects on environment, ozone layer, and depletion of fossil fuels and others, which represents a real difficult problem and this calls to development environmentally friendly and energy-saving technologies [1-4]. Solar energy is one of the renewable and environmentally sustainable energies as well as one of the promising energies because it is available in abundance. Therefore, at the present time, the academic and industrial Institutions are very interested in employing solar thermal energy and making it to operating cooling systems [5-11]. DX cooling systems are the most widely used in auto, homes and public buildings among other cooling cycles, simple in configuration and easier to maintain compared with central cooling systems which using water cooling tower. Therefore, the research process continues to improve the performance of DX air conditioners using solar energy [12, 13]. Al-Ugla et al. In 2016 [14] confirmed that DX air conditioning systems consume about $65 \%$ of the electrical energy in the construction sector in Saudi Arabia, and energy savings lie in the use of solar energy. La et al. 2011 [15] combined a vapour compression air conditioning system with a two-stage dehydrator cooling system with a flat-plate solar thermal collector $90 \mathrm{~m}^{2}$ with an experimental and theoretical study of the system using the TRNSYS simulation studio. The test was conducted in three cities in Beijing, Shanghai and Hong Kong for the purpose of demonstrating energy savings. The results showed that the cooling capacity was improved by $35.7 \%$, the electric COP was 11.48 , the thermal improvement was 1.0 and the electrical energy consumption was reduced by $31 \%$. By Bojido et al. [16], different control strategies for installing a solar cooling system in an office building were presented and compared and data disseminated for the actual operation of three summer cycles with the system operating at partial load. The results showed that a better performance could be achieved when using the control process in the regulation strategies of absorption chillers to correct the partial load compared to the conventional closed-loop system. By Bergero et al. [17], A hybrid air conditioning system consisting of an air dehumidification system working with a lithium chloride $\mathrm{LiCl}$ solution was used and combined with a reverse steam pressure system for the purpose of achieving great energy savings. A comparison is made of the proposed system with the conventional system, which features an evaporator operating at a higher temperature than the conventional one. The results showed that energy savings exceed $60 \%$ when compared to the baseline system. By Fong et al. [17], He studied and compared five different types of solar cooling systems for the

\footnotetext{
* Corresponding author: ahmedkhaleel18@yahoo.com
} 
subtropical city of Hong Kong with the aim of determining which system was the most energy efficient. It was carried out on the following solar energy cooling systems: a solar electric vapor pressure cooling system, a solar mechanical vapor compression cooling system, a solar absorption cooling system, a solar adsorption cooling system, and a solid solar dryer cooling system. The performance evaluation results showed that the solar electric vapor compression cooling and solar absorption cooling systems represent the highest performance and energy saving over other systems after the performance criteria were; Performance coefficient (COP), solar thermal gain, power consumption, and solar fraction.

\section{The new design of the system}

The solar air conditioning system is difference from the traditional system by adding a solar thermal collector to the refrigeration cycle to form a hybrid refrigeration cycle consisting of six basic parts an evaporator, a compressor, a solar thermal collector with storage tank, a condenser and an expansion device, and 3 gate valves to control the direction of the refrigerant flow as shown in figure 1. The mixture of liquid and vapor refrigerant enters the DX evaporator unit at low pressure and low temperature (point 1). In evaporator the refrigerant is heating up by absorbing the heat from the warm room air and then leaving it in cool saturated gas state (point 2). After that, the refrigerant gas enters the compressor to raise its pressure and temperature to be superheated gas (point 3). Valves which installed after compressor for control gas refrigerant direction by make ability to system to adding or isolating the solar thermal collector, the purpose to make comparison between conventional air conditioner system and solar hybrid air conditioner system by show the benefit of the added thermal energy to the system to save energy and improve performance. Evacuated tube solar collector type was used and combined it with the cooling cycle to capture the thermal energy from the falling solar radiation on the device by heating the water and keeping it inside a thermally insulated tank that contained inside a heat exchanger coil that exchange heat with the refrigerant gas coming out from the compressor before entering the condenser for the purpose of raising its temperature and pressure to the required state (point 4 ), which in turn reduces the rate of energy consumption on the compressor while improving the performance of the refrigeration cycle. When the ambient temperature increases, the convection inside the building increase and at the same time the thermal energy in the storage tank increase and this led to rise the water temperature to be higher than the temperature of the refrigerant gas leaving the compressor, this occurs in the summer because of high temperatures. When want to works with the conventional system should be closed valves before and after storage tank and open the valve that installed in direct line to condenser to isolate the solar thermal collector from the system. The refrigerant gas coming out from the solar collector enters to the condenser at high temperature and high pressure (point 5 ), in condenser were rejected overall heat that added by evaporator, compressor and solar collector to the ambient, gradually, first de - superheated refrigerant gas, second condensate saturated refrigerant gas, and then to be a sub-cooled refrigerant liquid (point 6). The expansion device it is a capillary tube reduces the refrigerant pressure from condenser pressure to evaporator pressure to return it to the evaporator in a liquid state at low pressure and low temperature.

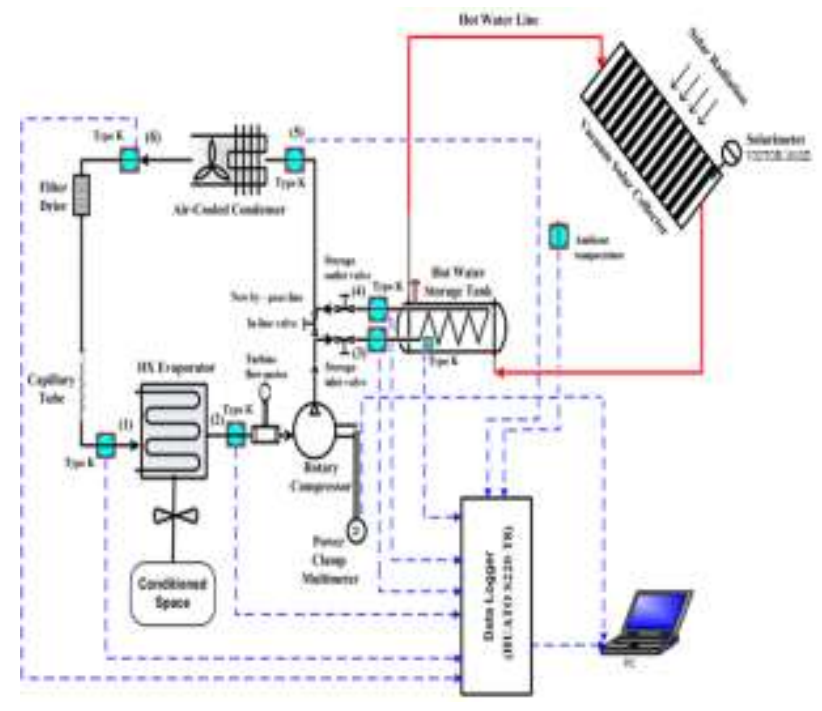

Fig. 1. Schematic diagram of a solar cooling system.

\section{The experimental setup}

In the experimental setup, a room, a test apparatus, and measuring devices were used. The current work describes the method of combining the direct expansion air conditioner with the solar collector that is installed after the compressor and as shown in the schematic diagram 2. The experimental setup consists first: from a test room whose dimensions are $\left(\begin{array}{lllll}4 & \times & 2.5 & \text { x } & 3\end{array}\right) \mathrm{m} 3$ containing from the inside the indoor unit with measurement devices, data recorder and laptop, and from the outside the outdoor unit that integrated with the solar collector as shown in figures 3 and 4 respectively. Second: A split unit air conditioning type tosot 2 ton was used as a test device installed with supply and return tubes between the indoor and outdoor units. The indoor unit contain a direct expansion evaporator made of copper tubes with aluminium fins coated in a brass finish and it is insulated from the sides with a heat insulator. The outdoor unit is equipped with a rotary compressor manufactured by ZHUHAI LANDA company with a capacity of 2 ton, but to save electric energy and make more use of solar thermal energy, it was replaced by another compressor during the experiments, with a smaller size and capacity of 1.5 ton manufactured by HIGHLY company, as shown in Figure 3. The condenser in the outdoor unit type air-cooled with tiered copper tubes with stainless brass-colour fins. The expansion device is a capillary tube installed in the outdoor unit. The system operates with R410A environmentally friendly refrigerant, the charge weight of the system is $1.8 \mathrm{~kg}$. The solar thermal collector was integrated with 
the outdoor unit at tilted angle 45 degrees and was directed towards south of Baghdad city. It contains a cylindrical horizontal tank to storage hot water and thermally insulated with a foam material layer $5 \mathrm{~cm}$ thick, and it contains from the inside a copper coil that was manufactured and wrapped locally and planted inside the tank. All details parts and specifications of the test rig are mentioned in Table 1.

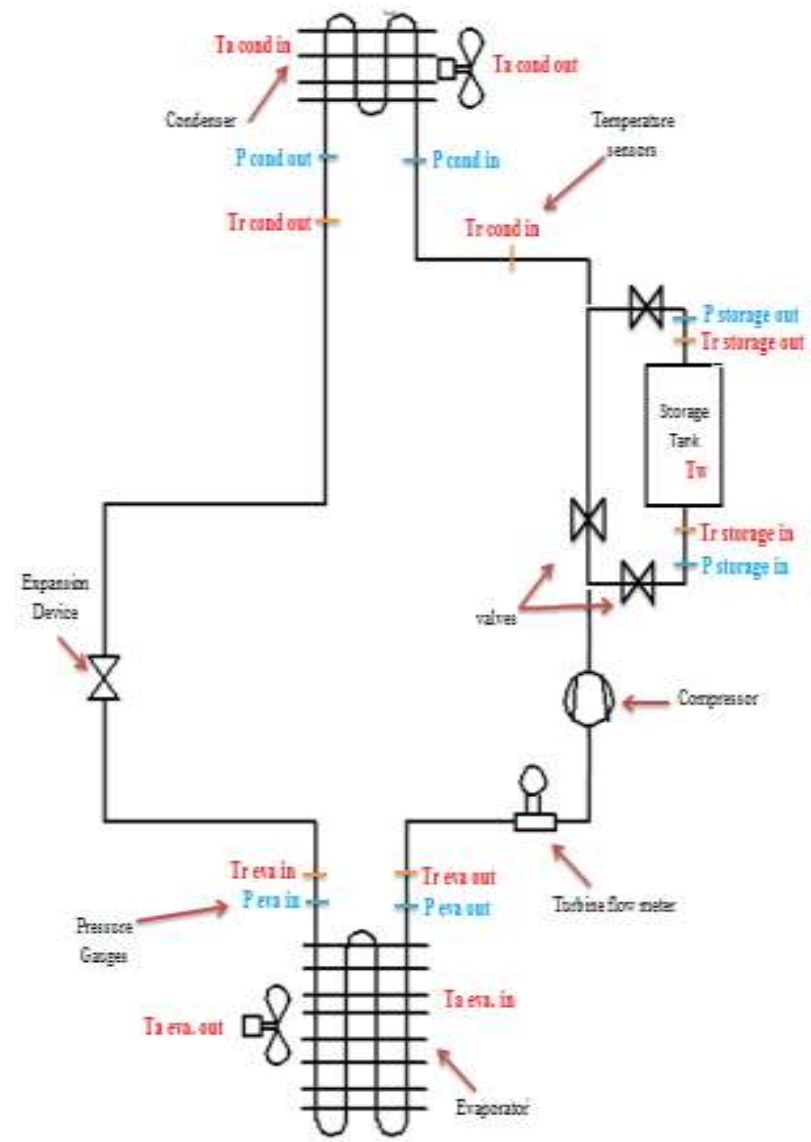

Fig. 2. Schematic diagram for the components of a hybrid air conditioner system.

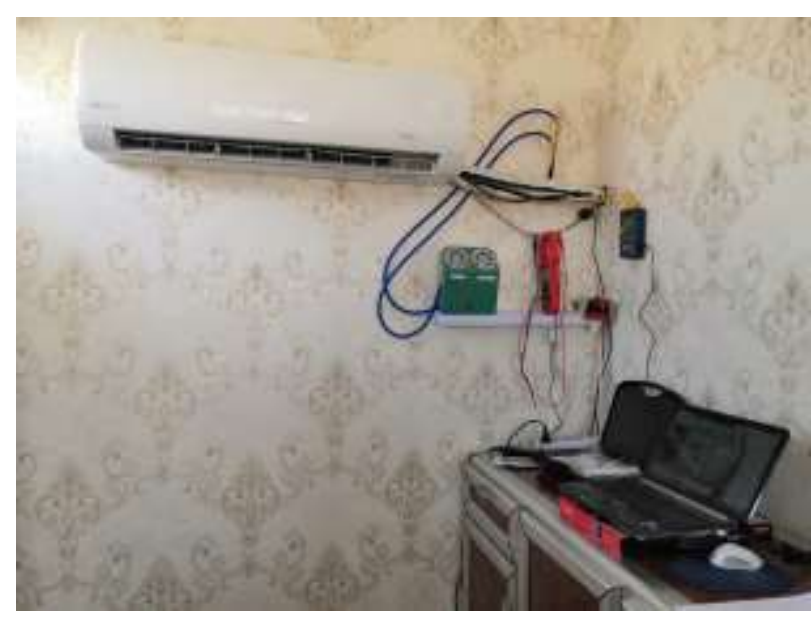

Fig. 3. Indoor unit with measuring devices, data recorder and laptop.

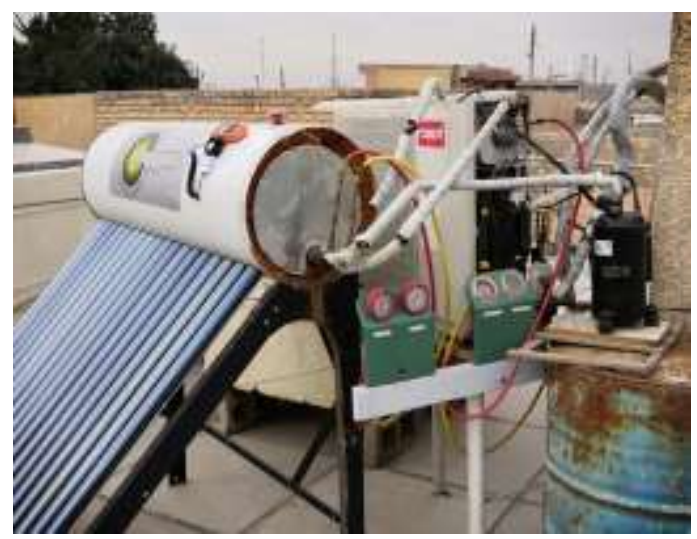

Fig. 4. The outdoor unit integrated with the solar collector.

Table 1. Specification of hybrid air conditioner system.

\begin{tabular}{|c|c|c|}
\hline $\begin{array}{l}\text { Air conditioner split unit } \\
\text { model }\end{array}$ & \multicolumn{2}{|c|}{ TS-H246OZM3 } \\
\hline Series & \multicolumn{2}{|c|}{ Moon } \\
\hline Compressor type & \multicolumn{2}{|c|}{ Rotary } \\
\hline Power supply & \multicolumn{2}{|c|}{$220-240 \mathrm{~V} / 1 \mathrm{PH} / 50 \mathrm{~Hz}$} \\
\hline Cooling capacity & \multicolumn{2}{|c|}{$24000(\mathrm{Btu} / \mathrm{h})$} \\
\hline Cooling current & \multicolumn{2}{|c|}{$10(\mathrm{~A})$} \\
\hline Input Power & \multicolumn{2}{|c|}{$2040-2180(\mathrm{~W})$} \\
\hline Refrigerant type/ charge & \multicolumn{2}{|c|}{$\mathrm{R}-410 \mathrm{~A} / 1800(\mathrm{~g})$} \\
\hline Expansion Device & \multicolumn{2}{|c|}{ capillary tube } \\
\hline Condenser coil & \multicolumn{2}{|c|}{ Copper tubes, aluminum flat fins } \\
\hline Length of tube & \multicolumn{2}{|c|}{$87(\mathrm{~cm})$} \\
\hline Condenser motor fan & \multicolumn{2}{|c|}{ Propeller } \\
\hline Number of tubes & \multicolumn{2}{|c|}{60} \\
\hline Evaporator coil & \multicolumn{2}{|c|}{ Copper tubes, aluminum flat fins } \\
\hline Length of tube & \multicolumn{2}{|c|}{$86(\mathrm{~cm})$} \\
\hline Number of tubes & \multicolumn{2}{|c|}{40} \\
\hline Air Flow & \multicolumn{2}{|c|}{$1250 \mathrm{~m}^{3} / \mathrm{h}$} \\
\hline \multicolumn{3}{|c|}{ Connection pipes } \\
\hline Location & Length $(\mathrm{cm})$ & Diameter (in) \\
\hline $\begin{array}{c}\text { Pipe from compressor to } \\
\text { tank }\end{array}$ & 115 & $1 / 2$ \\
\hline Pipe from tank to condenser & 120 & $1 / 2$ \\
\hline $\begin{array}{l}\text { Pipe from capillary to } \\
\text { evaporator }\end{array}$ & 480 & $1 / 4$ \\
\hline $\begin{array}{l}\text { Pipe from evaporator to } \\
\text { compressor }\end{array}$ & 480 & $5 / 8$ \\
\hline \multicolumn{3}{|c|}{ Storage tank } \\
\hline Diameter & \multicolumn{2}{|c|}{$42 \mathrm{~cm}$} \\
\hline Length & \multicolumn{2}{|c|}{$139 \mathrm{~cm}$} \\
\hline Storage capacity & \multicolumn{2}{|c|}{$120 \mathrm{~L}$} \\
\hline \multicolumn{3}{|c|}{ Collector } \\
\hline Number of tubes & \multicolumn{2}{|c|}{18} \\
\hline Inside diameter $(\mathrm{cm})$ & \multirow{2}{*}{\multicolumn{2}{|c|}{$3.7 \mathrm{~cm}$}} \\
\hline Outside diameter $(\mathrm{cm})$ & & \\
\hline Clearance between tubes & & $5 \mathrm{~cm}$ \\
\hline Length of tube & & $0 \mathrm{~cm}$ \\
\hline $\begin{array}{l}\text { Length of tube exposed to } \\
\text { the sun }(\mathrm{cm})\end{array}$ & & $7 \mathrm{~cm}$ \\
\hline Coil i & de the tank & \\
\hline coil type & & pper \\
\hline Shape & & iral \\
\hline diameter & & $2 "$ \\
\hline Length & & $\mathrm{cm}$ \\
\hline cycle diameter & & $\mathrm{cm}$ \\
\hline Number of cycle & & Cycle \\
\hline & alves & \\
\hline 3 & & 3 \\
\hline Gate, copper & Gat & copper \\
\hline $1 / 2$ in & & in \\
\hline
\end{tabular}

Third: Various high-precision measuring devices were used for the purpose of measuring and recording all 
operating variables. 1- Digital Power Meter [UT233] for measuring voltage, current, active power, apparent power, reactive power, power factor, phase angle, frequency, active power and phase relay. 2- SM series turbine flow meters, type SM - 15 - 63 with meter display screen. 3- Type (K) thermocouples of English origin distributed to each part of the test device for the purpose of indicating temperatures. 4- Data logger (HUATO S220- T8) connected to 8 type (K) thermocouples with an interval set every 3 minutes to record data as a Microsoft Excel worksheet on the computer. 5- Bourdon pressure gauges (BTC) distributed in two low pressure type before and after evaporator and four high pressure types before and after solar collector and before and after air cooled condenser. 6- Digital meter [MS6252B] for measuring the ambient temperature, ambient relative humidity, velocity and amount of air before and after the evaporator and condenser, and the temperature and relative humidity inside the room. 7- Solar radiation meter VICTOR $1010 \mathrm{D}$ to measure the rate of solar radiation falling on the test device to find out the rate and amount of thermal energy transferred during the testing hours to the solar thermal collector. All necessary tools and equipment were used for the purpose of cutting, polishing, expanding, welding, discharging, charging and indicating the weight of the shipment for the purpose of operating the device as required. The test device was initially vacuum up from the air by a vacuum pump and checked for leakage, then the cooling system was charged $(1800 \mathrm{~g})$ with the refrigerant ( $\mathrm{R} 410 \mathrm{~A})$. Continuous field tests were conducted to monitor system performance for 10 hours per day and during peak hour in Baghdad air conditions, and all measured data were monitored. All measured data were then saved for analysis later.

\section{Results and Discussion}

The test device was installed as required to be ready for experimental work and to take the required readings for purpose of studying the effect of the process of integrating the traditional air conditioner with the vacuum-tube solar collector that was installed after the compressor and to know its effect on the coefficient of performance and reduce energy consumption of the system. The effect of the ambient temperature and its effect on the system was also taken into consideration, and effect of changed the traditional compressor 2 ton by another one smaller than it, with capacity 1.5 ton. For the purpose of calculating and comparing the cooling capacity results, the CoolPack package was used.

Data were recorded and analyzed for comparison between three cases, the first case for a conventional air conditioner works with a 2-ton compressor, the second case for an air conditioner works with a 2-ton compressor and combined with a solar thermal collector, and the third case same as second case but were replaced the compressor with a capacity 1.5 ton. The results of comparison between temperatures which enters and outers from the condenser for the above three cases showed in Fig. 5. the amount of temperatures difference which enters and leaves the condenser are higher in the second case than the first and the third case and in the third case higher than the first case. That means the heat rejected in condenser with hybrid system more than with conventional system due to temperature of refrigerant gas that enters condenser more than ambient temperature, and especially in the second case due to compressor size. The results comparison in Figure 6 showed that the temperatures which enters the evaporator for the three cases are approximately equal, while the leaving from the condenser are different, as shown for the first case are higher than second and third cases, and in the second case higher than the third case. Due to the condenser efficiency with the hybrid system reject heat more than with conventional, and especially in the third case because small compressor size. Figure 7 shows the comparison results between the coefficient of performance for the three cases, showed that the performance for the third case higher than the first and the second cases, and for second case higher than the first case, the reason in the third case was used compressor 1.5 ton, that make the difference pressure between the condenser and the evaporator lower than in the first and second cases but keeping the refrigerant gas higher than the ambient temperature, and in the second case due to the higher superheat refrigerant gas before condenser make its efficiency better than with the first case. Figure 8 shows that the lowest energy consumption rate is with the third case, due to the small size of the compressor 1.5-ton comparison with 2 ton, while for the first and second cases approximately equal due to the compressor have the same size 2 ton and at the constant speed.

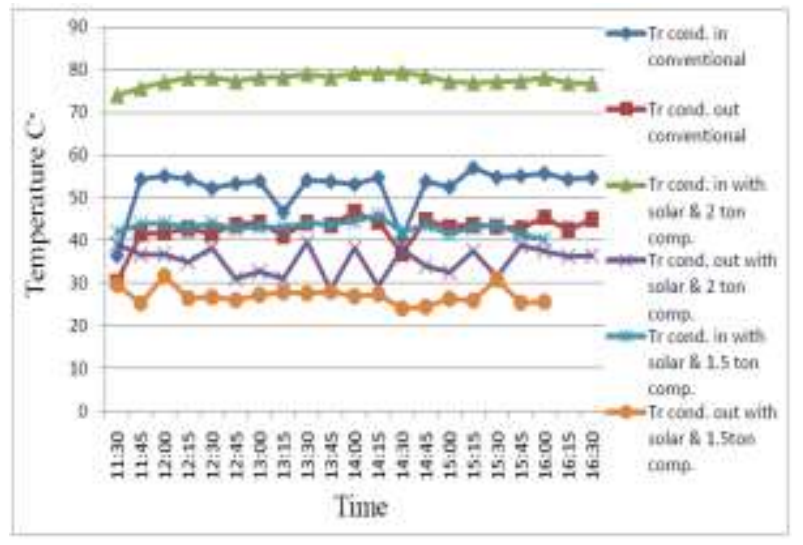

Fig. 5. Temperatures entering and leaving the condenser. 


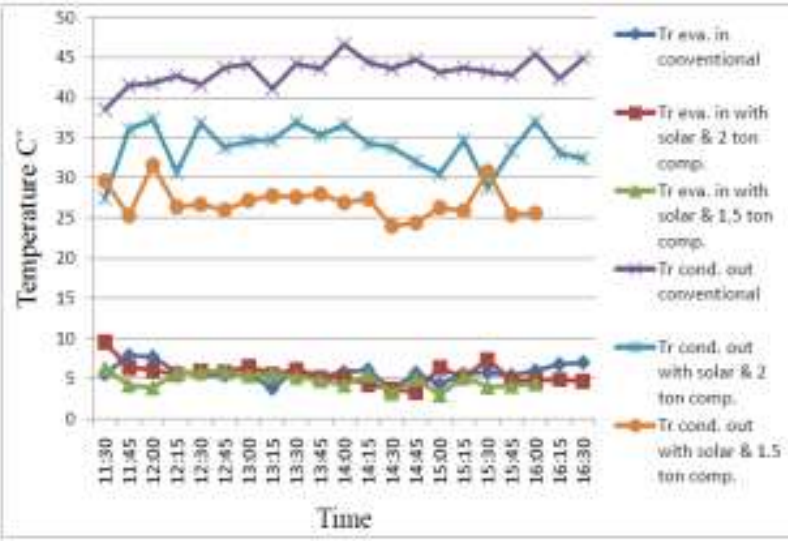

Fig. 6. Temperatures leaving the condenser and entering the evaporator.

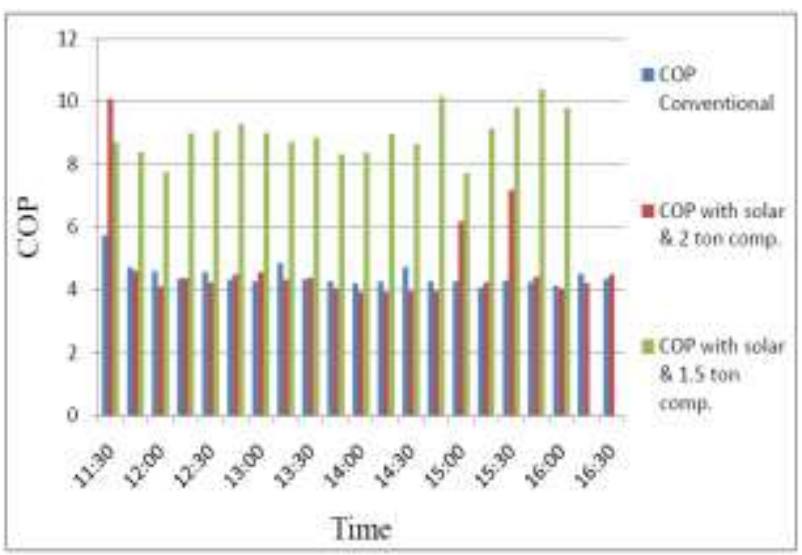

Fig. 7. Coefficient of performance for systems.

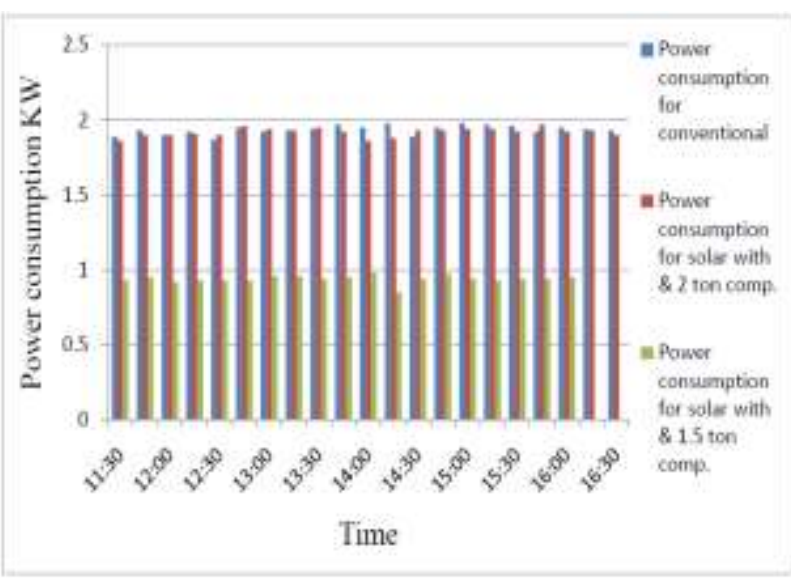

Fig. 8. Power consumption for systems.

\section{Conclusions}

In this paper, we present a new solar hybrid air conditioner design to demonstrate the potential of using solar energy to improve system performance and economize electrical energy. A solar thermal collector has been added after the compressor in order to add thermal energy to the system and reduce the energy consumption of the compressor. Modern simulators have been used to determine the optimal set points for the temperature of the refrigerant leaving the water storage tank and entering the condenser as a reference. The experiments on the test apparatus were carried out in three cases, first conventional, second with 2-ton compressor and with solar collector, and third with solar collector but with replacing the compressor by another one size 1.5 ton. The coolpack program was used for the purpose of data analysis. The results showed that the refrigeration cycle system showed that the new design provides higher system performance compared with the traditional system. A new design model for an air conditioning system that uses solar energy has been presented to demonstrate the possibility of using solar energy to improve system performance and reduce electrical energy consumption by adding a solar thermal collector after the compressor to add thermal energy to the system and reduce the energy consumption on the compressor. The practical results proved that the new design gives COP of 9.87 instead of 4.27, which increases COP by $52.5 \%$ and reduces the rate of energy consumption by $52 \%$.

\section{References}

1. Y. Vankov, A. Al-Okbi, M.H. Hasanen, Solar hybrid air conditioning system to use in Iraq to save energy, E3S Web of Conf. EDP Scien., 124 (2019)

2. I. Dincer, M. Kanoglu, Refrigeration systems and applications (Vol. 2, New York: Wiley, 2010)

3. J.A. Duffie, W.A. Beckman, Solar engineering of thermal processes (John Wiley \& Sons, 2013)

4. J.N. Abed, K.K. Al-Chlaihawi, Experimental Evaluation of Thermal Performance of Solar Assisted Vapor Compression Heat Pump, J. of Engin. 145-160 (2015)

5. N.A. Nader, A.M. Ibrahim, A.S. Rami, Hybrid air conditioning, solar, HVAC, energy consumptions, Inter. J. of Modern Eng. Res., 34-32 (2016)

6. E.V. Iakovleva, D.D. Guerra, Improving the efficiency of the use of photovoltaic stations in the republic of Cuba, Journal of Physics: Conference Series 1753(1),012056 (2021)

7. N. Ponomareva, A. Zvereva, E. Golubtsova, S. Ilyashenko, G. Ivanov, Certain economic instruments as a factor of realizing the potential of using alternative energy sources in Russia, E3S Web of Conferences 124,05066 (2019)

8. C. Savard, E.V. Iakovleva, A suggested improvement for small autonomous energy system reliability by reducing heat and excess charges, Batteries 5(1),29 (2019)

9. A.R. Trott, T.C. Welch, Refrigeration and air conditioning (Butterworth-Heinemann, 1999)

10. D.S. Kim, Feasibility of a compact heat recovery ventilator module with an integrated air-cooled solar absorption air-conditioner, Inter. j. of ther. sci., 1604-1614 (2011)

11. N. Audah, N. Ghaddar, K. Ghali, Optimized solar-powered liquid desiccant system to supply 
building fresh water and cooling needs, Appl. energy, 3726-3736 (2011)

12. L. Zheng, D. Shiming, An experimental study on the inherent operational characteristics of a direct expansion (DX) air conditioning (A/C) unit, Build. and Enviro., 42.1, 1-10 (2007)

13. V. Vakiloroaya, J.G. Zhu, Q.P. Ha, Modelling and optimization of direct expansion air conditioning system for commercial building energy saving, Procee. of the 28th Intern. Sympo. on Autom. and Rob. in Const. ISARC (2011)

14. A.A. Al-Ugla, M.A.I. El-Shaarawi, S.A.M. Said, A.M. Al-Qutub, Techno-economic analysis of solar-assisted air-conditioning systems for commercial buildings in Saudi Arabia, Renew. and Susta, Energy Reviews, 54, 1301-1310 (2016)

15. D. La, Y. Dai, Y. Li, T. Ge, R. Wang, Case study and theoretical analysis of a solar driven twostage rotary desiccant cooling system assisted by vapor compression air-conditioning, Solar energy 85.11, 2997-3009 (2011)

16. L.A. Bujedo, J. Rodríguez, P.J. Martínez, Experimental results of different control strategies in a solar air-conditioning system at part load, Solar energy, 85.7, 1302-1315 (2011)

17. S. Bergero, A. Chiari, On the performances of a hybrid air-conditioning system in different climatic conditions, Energy, 36.8, 5261-5273 (2011)

18. K.F. Fong, T.T. Chow, C.K. Lee, Z. Lin, L.S. Chan, Comparative study of different solar cooling systems for buildings in subtropical city, Solar Energy, 84.2, 227-244 (2010). 